affective cravings which are either unjustifiable or ungratifiable, and which lead either to desperate repression or social regression and indulgence.

Various types of neuroses are described, and many cases quoted, which illustrate the different methods of struggling with and adjusting jeopardizing cravings so as to prevent a 'fear state' of the autonomic apparatus. The author groups psychotherapeutic principles into two general systems : (1) Suggestion method; (2) Psycho-analytic method; and advocates a sensible use of the reconstructive suggestion method following the psychoanalytic readjustment.

The article is far too extensive to be abstracted in any detail, but it is very suggestive and stimulating.

R. Dansie.

\title{
TREATMEN'T.
}

[47] Contributions to psychotherapeutic technic through psychoanalysis.-S. E. JelliffFe. Psycho-analytic Rev., 1919, vi, 1.

Some of the light which Freud has turned upon mental problems, and upon which he bases his therapy, is here briefly described. Ferenczi has shown that the production of the hypnotic state depends upon transference, and that the apparent suggestion introduced is only the spontaneous upspringing of impulses and ideas already present in the unconscious. Suggestibility, then, whether in the unconscious or conscious state, is the readiness to pour out unconscious previously-inhibited content because of the transference factor. Advances in therapy lie rather in setting free from within tendencies already there, than in the introduction of new ideas from without. To impose occupation and amusement from without is to invite failure; but to allow the patient to use old paths of interest and find them leading out through their very original value to constructive contact with environment, leading now outwardly, no longer only within, is in line with these natural advances. Wide employment of the means at hand in the world of real interests and mutual problems, is a most rational but too much neglected form of psychotherapy.

Special points in the technique of psycho-analysis in dementia pracox are brought forward. The difficulties of transference are great. The libido is bound in the accumulated affectivity which the original complex situation has gathered to itself, so that in many cases it is impossible to bring the affect to consciousness. The affect guards itself too jealously, and a special form of approach might be of great advantage. This is the establishment of a triangular transference, so that the affect is not put too strongly on the defensive, and too strong an erotic situation is thus avoided. In dementia praccox, therefore, transference may be accomplished not toward one person but two. The specially-trained nurse or attendant would allow of this distribution of interest. In minor mal-adjustments there is demand for some variations in the mode of approach. The sex of the analyst is often important, because of unconscious homosexual tendencies. The female paranoiac may often be better handled by a woman analyst, as well as the female compulsive neurotic, excitable, hysteric, and 
manic patient. The analysis is then more likely to run more smoothly, a better emotional attitude is gained, and dangers in the first intensity of the transference when the free floating libido is seeking satisfaction is lessened. The sensitive, over-prudish woman patient is also saved from resistances and the likelihood of negative transference being set up.

C. Stanford Read.

\section{EDITORIAL NOTICES.}

THE EDITORIAL COMMITTEE will welcome original articles for publication in the Journal. They should be addressed to Dr. S. A. Kinnier Wilson (Neurology); Dr. Bernard Hart (Psychopathology); the Editorial Secretary, Journal of Neurology and Psychopathology, Bristol; or to any other member of the Editorial Committee. The Copyright of papers appearing becomes the property of the Journal unless the authors state before publication that they reserve the rights to themselves.

They also invite correspondence, criticisms, and suggestions from readers, which may aid in the development of the Journal.

Contributions should be as concise as possible, and be forwarded at least six weeks before the date of publication. Papers are best type-written, and carefully revised, since alterations in type are costly. References should be made in the following order :year-volume-page-and be inserted in brackets in the text where they occur, thus : (Brit. Med. Jour. 1912, ii, 579). Where practicable, articles should conclude with a short summary of their contents.

Illustrations.-These, whether plain or coloured drawings, or photographs, should be rendered as perfectly as possible. The Publishers undertake the preparation of the blocks, but not of the originals.

Reprints.-Owing to the present abnormal costs of production, free reprints of articles cannot be given until further notice. If desired they may be obtained by payment, but notice must be given when the proof is returned.

Subscriptions. - 30/- net post free ; single numbers, 8/6 net.

Business Communications should be addressed .John Wright \& Sons Ittd., Journai. of Neurology and Psychopathology, Bristol.

Sole Agents for the United States of America, William Woon \& Co., 51, Fifth Avenue, New York, to whom American subscriptions should be sent. 